\title{
An Optimum Design for Activated Sludge Systems
}

\author{
By Saziye Balku* \\ Magdi Buaishat \\ Seniz Ozalp-Yaman
}

The high costs of construction, maintenance and operation of waste water treatment systems exert economic pressure, even in developed countries. Therefore, engineers look for creative, cost-effective environmentally sound ways to control pollution. In this study, how an optimization algorithm can be used to determine the design parameters of an activated sludge system which make the cost minimum is presented. The cost of an investment can be analyzed in two categories: fixed capital investment and operational costs. For an activated sludge system, the former consists of an aeration tank, settling tank, pumps, piping system, aeration system and scraper constructions, whereas the latter mainly involves energy costs for aeration and sludge removal when labor or nonoperational expenditures are ignored. For a defined inlet flow rate and the characteristics of wastewater and for the desired outlet characteristics, optimum design parameters can be determined using that optimization algorithm. The Activated Sludge Model No.3 and Takács settling model have been used in modeling the activated sludge system. Simulations are executed in Matlab ${ }^{\circledR}$ and fmincon (active-set algorithm) is used as optimization algorithm with some improvements. The proposed algorithm can be a good choice for the design of activated sludge systems. The recycle ratio, the waste sludge ratio and the oxygen transfer rate in the aeration pond are the most important parameters in the energy cost and so, in the operational cost. The sizes of aeration and settling tanks are the most important parameters of fixed capital investment. The results show that the volume of the aeration tank, settler area, recycle ratio and the waste ratio can be lowered by $26.79 \%, 49.21 \%, 20.90 \%$, and $44.42 \%$ respectively by the application of the algorithm. The investment and operational costs of an activated sludge system can be lowered consequently.

Keywords: Activated sludge systems, algorithm, ASM3, cost, optimization

\section{Introduction}

The aim of this paper is to determine the optimum design parameters for the activated sludge systems consisting of an aeration pond and settler using an optimization algorithm in a simulation method. A serial-three-stage simulation is

\footnotetext{
* Associate Professor, Atilim University, Turkey.

* PhD Student, Atilim University, Turkey.

${ }^{+}$Professor, Atilim University, Turkey.
} 
performed within an optimization algorithm where the minimum cost (investment and operational) is defined as an objective function. Activated sludge is a process which is used in the biological treatment of waste water. It has been used since 1914 when Arden and Lockett first applied it, in order to increase the treatment capacity. The basic idea of the process is to maintain the 'active sludge' suspended in wastewater by means of stirring and aeration. The biomass uses the organic material as its energy source in the process with oxygen or another oxidation agent. A sedimentation tank is added to the end of the process where the biomass is transported towards the bottom by gravity settling, and is either circulated back to the biological process or removed from the system as excess sludge. The treated wastewater is withdrawn from the top of the sedimentation tank and released either for further treatment or directly into a receiving medium (Jeppsson, 1996). Many problems are encountered in the simulation and the optimization of an activated sludge and a settler model especially when they are treated as combined. Since the design variables for the treatment system and the concentrations of the model components in the ponds under normal operation conditions are not known and the kinetics and dynamics of the system are very complex.

Several optimization and simulation studies have been carried out in the recent years related to wastewater treatment plants. Iqbal and Guria (2009) have formulated their optimization problems according to a present construction and on the operation. Holenda et al. (2008) apply a model predictive control for the dissolved oxygen concentration in an aerobic reactor. The COST 682 Working Group No.2 (Copp, 2002) develops a benchmark for evaluating by simulation and control strategies. Chachuat et al. (2005) made a study on optimal aeration control of industrial alternating activated sludge plants. Balku and Berber (2006) use a set of different parameters which describe a wastewater treatment system using a general approach and trial - error - method. Li et al. (2013) simulate a full-scale oxidation ditch process by the ASM2d model and optimize for the minimal cost on ammonium and phosphorus removal considering the operational costs related with aeration energy and sludge production. Rojas and Zhelev (2012) study the energy efficiency in thermophilic aerobic digestion. Gernaey et al. (2004) review and focus on white-box modeling. Ferrer et.al (2008) presents a software tool, to design, simulate and optimize wastewater treatment plants, which is called DESASS (Design and simulation of Activated Sludge Systems). Neither of those studies considers minimizing the design parameters of an activated sludge system.

In the present study, the design parameters which make the cost of an activated sludge system minimum are determined by an optimization method. In order to reach its aim, this work uses the Activated Sludge Model No.3 (Gujer et al. 1999) amongst the other models (Henze et al., 2002) and settling model by Takács et al. (1991) together with a standard optimization algorithm (fmincon) included in MATLAB ${ }^{\circledR}$ (The Mathworks, 2006).

The optimization problem arising from the present work has been described by a complex mathematical model (e.g., sets of differential-algebraic equations) and a general complex process optimization problem may be formulated as follows: 
Find $x$ to minimize:

$C=\phi(\dot{x}, x, y)$

subject to $f(\dot{x}, x, y)=0$

$x\left(t_{0}\right)=x_{0}$

$h(x, y)=0$

$g(x, y) \leq 0$

$y^{L} \leq y \leq y^{U}$

where $y$ is the vector of the decision variables; $C$ is the cost (objective function) to minimize; $f$ is a function describing the complex process model; $x$ is the vector of the states (and $\dot{x}$ is its derivative); $t_{0}$ is the initial time for the integration of the system of differential algebraic equations (and, consequently, $x_{0}$ is the vector of the states at that initial time); $h$ and $g$ represent possible equality and inequality constraint functions and, finally, $y^{L}$ and $y^{U}$ are the upper and lower bounds for the decision variables, respectively (Egea, 2010). The differences of our optimization problem with the above optimization problem are that, the objective function is linear and the problem does not have any equality constraints. An optimization technique proposed by Biegler and Grossmann (2004) has been utilized.

\section{Optimization Problem and Solution Algorithm}

The optimization problem consists of a linear objective function and many equations relating to mass balances and non linear constraints and boundaries on system variables. The objective function, in which the most important design variables effecting the investment and the operational costs of an activated sludge system are considered, is formulated. The investment cost is the total of the purchasing, construction, and other related costs for the aeration and the settler tank, the recycling pump, the waste sludge pump, the aerators, and the piping. The operation cost involves the energy used for aeration and pumping, and other operational costs related with the sludge disposal.

The design variables are presented as follows:

1. Size of the aeration tank;

2. Area of the settler;

3. The recycle ratio;

4. The waste sludge ratio; and

5. The liquid phase volumetric mass transfer coefficient.

The aeration tank and the settler sizes affect investment costs, while the recycle and the waste sludge flow rate impact both the investment and the operational costs. The liquid phase volumetric mass transfer coefficient $\left(k_{L} a\right)$ affects the investment cost (aerator capacity) along with the operational cost (energy). 
Under these conditions, the optimization problem can be defined as a minimum cost problem since:

$\min f=\alpha \times V_{a t}+\beta \times A_{c}+\theta *\left(\delta \times Q_{r s}+\varepsilon \times Q_{w}+\phi \times k_{L} a 3\right)$

where $\alpha, \beta, \theta, \delta, \varepsilon$, and $\phi$ are the cost functions related with either the fixed

capital investment or the operational cost, or both of them; $\theta$ is a weighing factor between the fixed capital investment and the operational costs. Also, where:

$V_{a t}$ : the volume of the aeration tank (the fixed capital investment);

$A_{c}$ : the cross sectional area of the settler (the fixed capital investment);

$Q_{r s}$ : the recycle flow rate (the fixed capital investment and the operational cost);

$Q_{w}$ : the waste sludge flow rate (the fixed capital investment and the operational cost);

$k_{L} a 3$ : the liquid phase volumetric mass transfer coefficient during the normal operation period (the fixed capital investment and the operational cost).

The objective function is subjected to the general model given in Eq. (8), where $\mathrm{X}$ is a 74-dimensional vector which is described in the section "The wastewater treatment plant model". The waste water treatment plant model:

$$
\frac{d X}{d t}=f(X)
$$

The system variables which affect the operation of the waste water treatment system are;

$\left[V_{a t}, A_{c}, Q_{r s}, Q_{w}, k_{L} a 1, k_{L} a 2, k_{L} a 3, t p 1, t p 2, t p 3\right]$. These ten system variables are determined by the optimization algorithm. Those which do not appear in the objective function but are still determined in the course of optimization algorithm are as follows:

$k_{L} a 1$ : the liquid phase volumetric mass transfer coefficient for the start-up period;

$k_{L} a 2$ : the liquid phase volumetric mass transfer coefficient for the conditioning period;

tp1: $\quad$ the length of start-up period (h);

tp2: the length of conditioning period (h);

tp3: the sample length of normal operation period (h).

\section{The Wastewater Treatment Plant Model}

The wastewater treatment plant model consists of an aeration and a settling tank model. In the aeration tank, ASM3 is considered for the modeling of microbiological processes in a single tank. The mass balances are:

$\frac{d X_{i}^{a t}}{d t}=\frac{Q_{i n} X_{i}^{i n}+Q_{r s} X_{i}^{r s}-\left(Q_{i n}+Q_{r s}\right) X_{i}^{a t}}{V_{a t}}+R_{i}$ 
where $X^{\text {at }}, X^{\text {rs }}$, and $X^{\text {in }}$ are 13-dimensional vectors consisting of ASM3 components in the activated sludge tank (at), recycle $(r s)$, and inlet waste water (in), respectively. The mass balance related to the dissolved oxygen $\left(S_{o}\right)$ includes an additional term on the right-hand side $+k_{L} a\left(S_{O}^{\text {sat }}-S_{O}^{a t}\right)$ representing the oxygen transfer, and the mass balance results in:

$\frac{d S_{O}^{a t}}{d t}=\frac{Q_{i n} S_{O}^{i n}+Q_{r s} S_{O}^{r s}-\left(Q_{i n}+Q_{r s}\right) S_{O}^{a t}}{V_{a t}}+R_{S_{O}}+k_{L} a\left(S_{O}^{\text {sat }}-S_{O}^{a t}\right)$

where " $k_{L} a$ " and "sat" represent the liquid phase volumetric mass transfer coefficient and saturation, respectively.

There have been many studies referred in Ekama et al. (1997) including Takács et al. (1991) which focused on the modeling of the settling tank in details. The settler is modeled as a cylindrical tank with 10 horizontal layers and the settling velocity model proposed by Takács et al. (1991) and adapted to the ASM3 components (Balku and Berber, 2006; Balku, 2007; Balku et al., 2009).

The general model is as follows;

$\frac{d X}{d t}=f(X)$

where $X$ is a 74-dimensional vector, 13 aeration tank variables, and 60 settling tank variables. The last variable is related to the deviation from the constraints for the effluent

$\frac{d X^{j}}{d t}=\max \left(0, C O D_{e f f}-C O D_{\max }\right)+\max \left(0, S S_{e f f}-S S_{\max }\right)$

where $\mathrm{j}$ is the index representing the $74^{\text {th }}$ state variable. $C O D_{\text {eff }}$ is calculated by its definition in $A S M 3$. In the course of integration, this differential equation represents the cumulative deviation from the constraints related to $C O D$ and $S S$. However, no constraint is assigned to the total nitrogen concentration in the effluent since denitrification is not the aim of this study. There are some other equations which set the relationships between the differential mass balances in the model. However, they are represented in terms of state variables and for this reason; no additional state variables are needed.

\section{The Algorithm for Optimization and Simulation}

The algorithm consists of mainly four stages:

1. Optimization: The optimization algorithm is defined in this section with the objective function, the constraints and the boundaries. The flow rate and the composition of the waste water entering the treatment system and initially existing in the aeration tank and the settler are given. The optimization algorithm conditions are selected.

2. Simulation: The program is referred to as a 'sub-program'. The activated sludge system is operated in three consecutive periods; start-up, conditioning, and normal operation. The inlet and the initial data are used first during the start-up period with the initial guesses of the design variables. The wastewater treatment algorithm is called in each period, and 
the results achieved from one period are used as the initial values for the next period.

3. Treatment plant model: All the mass balances, microbiological processes in the aeration and the settling tank expressions are involved in this subroutine. The relations between the mass balances in all the streams are presented here.

4. Constraints: All the inequality constraints are given under this algorithm. When the serial simulation is completed once, all the constraints are controlled and, if satisfied, the program is completed; otherwise new guesses for the system variables are assigned by the optimization algorithm, and all the computations are repeated until all the constraints are met.

\section{Application}

The inlet wastewater composition, the stoichiometric matrix, and the kinetic parameters (at $20{ }^{\circ} \mathrm{C}$ ) are taken from ASM3 (Activated Sludge Model No.3) without any changing (Gujer, 1999). The parameters involved in the settling velocity model are used as given by Takács et al. (1991) for a low-load feeding. The feed to the settler is at the $7^{\text {th }}$ layer from the top. In the recycling stream, the concentrations of $S_{\mathrm{O}}$ and $S_{\mathrm{N} 2}$ are assumed to be zero. The threshold concentration $X_{t}$ equals to $3000 \mathrm{~g} \mathrm{~m}^{-3}$. The inlet wastewater flow rate is taken as $Q_{\text {in }}$ : $1000 \mathrm{~m}^{3}$ day $^{-1}$.

System variables are converted into dimensionless figures by dividing them to the predefined values given in the literature (Balku, 2007) as follows:

Predefined values: $Q_{\mathrm{rs}}: 800 \mathrm{~m}^{3} \mathrm{day}^{-1} ; Q_{w}: 12 \mathrm{~m}^{3} \mathrm{day}^{-1} ; V_{\mathrm{at}}: 450 \mathrm{~m}^{3} ; A_{\mathrm{set}}: 113 \mathrm{~m}^{3}$; $k_{\mathrm{L}} a 1: 4.5 \mathrm{~h}^{-1} ; k_{\mathrm{L}} a 2: 4.5 \mathrm{~h}^{-1} ; k_{\mathrm{L}} a 3: 4.5 \mathrm{~h}^{-1}$;

only tp1, tp2 and tp3 values are extended twice when compared to the reported one (Balku, 2014), because of the high sludge retention time in the system such as tp1: $960 \mathrm{~h}$; tp2: $960 \mathrm{~h}$; tp3: $200 \mathrm{~h}$.

Dimensionless figures: A sample conversion is as follows:

$$
y 1=\frac{V_{a t, o p t}}{V_{a t}}=\frac{V_{a t, o p t}}{450}
$$

The system variables can be expressed in a dimensionless form as below:

$$
y=[y 1 ; y 2 ; y 3 ; y 4 ; y 5 ; y 6 ; y 7 ; y 8 ; y 9 ; y 10]
$$
follows;

The objective function (Eq. 7) can be defined in a dimensionless form as

$$
\min f=\alpha \times y 1+\beta \times y 2+\theta^{*}(\delta \times y 3+\varepsilon \times y 4+\phi \times y 7)
$$

The lower and the upper boundaries for the system variables are assigned for the dimensionless numbers as follows:

Lower Boundaries: 0.5;

Upper Boundaries: 3.0 
In the simulation algorithm, there are three periods: the start-up, the conditioning, and the normal operation periods. The first and second periods are unsteady, but the third one is tried to be kept steady.

The simulation for the start-up period of a plant is accomplished by starting with an aeration tank and a settler filled with the incoming wastewater. In this period, no sludge is removed from the system and the aim is to reach the required microorganism concentration in the aeration pond to provide a convenient treatment and a proper settling characteristics.

In the conditioning period with a sludge disposal, the sludge is started to be removed from the system. At the beginning of the sludge disposal, the concentration of the suspended solids and the related particulates in the aeration tank start decreasing to such an extent that is not required in the normal operation period, where it is preferred to be steady in terms of particulates as much as possible. For this reason, this period can be considered as a transient stage.

As a third stage, a normal operation period is simulated with a continuous sludge disposal, and both the DO concentration and the percent change of concentration of mixed liquor volatile suspended solids are controlled.

\section{Constraints}

Two additional constraints are present in this study when compared to the previous one (Balku, 2014). One is related with the hydraulic retention time and the other one is related with the sludge retention time.

\section{The Inequality Constraints}

a. The maximum constraints on the effluent are taken as (EU Commision Directives, 1991; 1998):

$$
\begin{array}{ll}
C O D_{\max }: 125 & \mathrm{~g} \mathrm{~m}^{-3} \\
S S_{\text {max }}: 35 & \mathrm{~g} \mathrm{~m}^{-3}
\end{array}
$$

and the effluent discharge criteria can definitely be controlled with the given differential equation (12). The maximum total deviation from the given constraint is 0.01 .

b. The dissolved oxygen concentrations in each period (start-up, conditioning, and normal operation) should be greater than $1.9 \mathrm{~g} \mathrm{~m}^{-3}$ and less than 3.0 for the normal operation period only.

c. The objective function should be positive.

d. The MLVSS (mixed liquor volatile suspended solids) change in the conditioning period should be less than 12 percent.

$$
\% \text { change in } M L V S S_{\text {conditioning }}=\frac{M L V S S_{\text {conditioning }}-M L V S S_{\text {start }-u p}}{M L V S S_{\text {conditioning }}}
$$

e. The MLVSS change in the normal operation period should be less than 1 percent.

$$
\% \text { change in } \operatorname{MLVSS}_{\text {normal }}=\frac{M L V S S_{\text {normal }}-M_{\text {LVSS }} \text { conditioning }}{M L V S S_{\text {normal }}}
$$


f. At the end of the start-up period, MLVSS should be between $2300 \mathrm{~g} \mathrm{~m}^{-3}$ and $4000 \mathrm{~g} \mathrm{~m}^{-3}$.

g. The maximum change in heterotrophic bacteria concentration should be less than $1 \%$ in the normal operation period in order to keep the period steady.

h. The overflow rate for the settler should be between 0.5 and $2 \mathrm{~m}^{3} / \mathrm{m}^{2} . \mathrm{h}$.

i. Hydraulic retention time $H R T=V_{a t} / Q_{\text {in }}$ is added to the inequality constraints. The minimum value is 5 hours and the maximum is 20 hours.

j. The other inequality constraint is related with sludge retention time (SRT) of the system and is determined by the following formula:

$$
S R T=\frac{\left(X_{H}+X_{A}\right) V_{a t}+\sum_{j=1}^{j=10}\left(X_{H}+X_{A}\right) h_{s e t, j} A_{s e t, j}}{\left(X_{H}+X_{A}\right)_{w} Q_{w}+\left(X_{H}+X_{A}\right)_{e f f} Q_{e f f}}
$$

The formula represents the total heterotrophic and autotrophic bacteria concentrations in the reactor and the settler divided by the total heterotrophic and autotrophic bacteria concentration leaving the system in the waste sludge and the effluent stream, where $\mathrm{j}$ is the number of the settler layer. The lower and upper constraints are given 5 days and 20 days.

\section{The Equality Constraints}

In the optimization problem, there is no equality constraint on the system.

\section{Flow Diagram for Optimization Algorithm}

The flow diagram for the optimization algorithm applied in this study is given in Figure 1. 
Figure 1. Flow Diagram for Optimization Algorithm

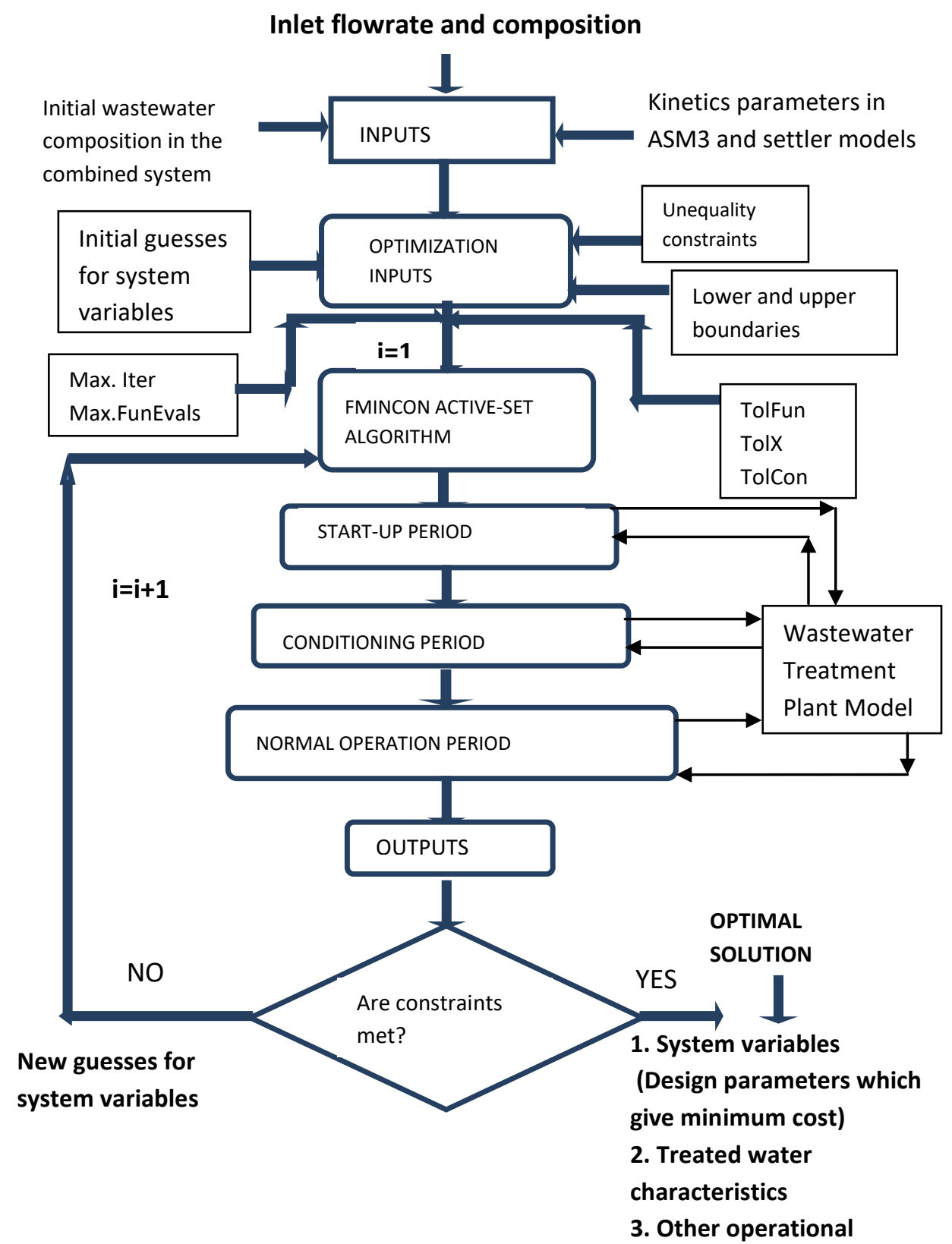

All computations are performed by an Intel(R) Core(TM)2 Duo CPU E8400 @ 3.00 GHz 2.67 GHz, RAM 4,00 GB computer, 64-bit. For the simulations MATLAB 7.10.0 software package and the 'ode15s' integrating routine of MATLAB with maximum step size of $0.1 \mathrm{~h}$ and 'fmincon' optimization subroutine are used with active-set option.

The results of the optimization algorithm are given in Table 1. After 13 iterations, a local optimum is found. 
Table 1. The Optimization Results

\begin{tabular}{|c|c|c|c|c|c|c|}
\hline & & & Max & Line search & Directional & First-order \\
\hline Iter & F-count & $f(x)$ & constraint & steplength & derivative & optimality \\
\hline 0 & 11 & 5 & 46.05 & & \multicolumn{2}{|c|}{ Infeasible start point } \\
\hline 1 & 22 & 3.61828 & 293 & 1 & -1.45 & 27.5 \\
\hline 2 & 47 & 3.61829 & 293 & $-6.1 e-005$ & -0.146 & 26.8 \\
\hline 3 & 58 & 3.72476 & 0.6637 & 1 & 0.304 & 29.6 \\
\hline 4 & 69 & 3.54742 & 0.2645 & 1 & -0.308 & $7.76 e+004$ \\
\hline 5 & 94 & 3.54745 & 0.2645 & $-6.1 e-005$ & -0.998 & 79.4 \\
\hline 6 & 108 & 3.48021 & 0.4805 & 0.125 & -1 & 92 \\
\hline 7 & 119 & 3.54893 & 0.01203 & 1 & 0.475 & 756 \\
\hline 8 & 130 & 3.25115 & 5.008 & 1 & -0.989 & 544 \\
\hline 9 & 141 & 3.23467 & 5.599 & 1 & -1.01 & 39.3 \\
\hline 10 & 152 & 3.2319 & 5.578 & 1 & -0.176 & 15.6 \\
\hline 11 & 163 & 3.87036 & 0.2139 & 1 & 0.827 & $2.88 \mathrm{e}+007$ \\
\hline 12 & 174 & 3.86639 & 0.1967 & 1 & -0.679 & 0.995 \\
\hline 13 & 186 & 3.7078 & 0 & 0.5 & -0.787 & $1.2 \mathrm{e}+003$ \\
\hline
\end{tabular}

The most important design parameters affecting the cost of a treatment system are assigned as the volume of the aeration tank, the area and the height of the settler tank, the recycle and the waste sludge, and the aeration and they form the objective function. The cost functions and the weighing factors are regarded as 1 for simplicity.

The other system variables in the start-up and conditioning periods-e.g., the time elapsed during these periods, and the liquid phase volumetric mass transfer coefficients- are not considered so important in the optimization problem since the processes at those periods take place only once during long periods of operation. Also, the operational cost in these periods is not accounted as significant as that of the normal operation period, which is continuous and regarded as steady. Similarly, the DO concentration and MLVSS are not taken as design variables since DO can be controlled during the simulation by $\mathrm{k}_{\mathrm{L}} \mathrm{a}$, and the MLVSS can also be controlled by the constraints on it. The DO constraint is necessary in order to prevent the growth of undesirable filamentous bacteria, and MLVSS constraint is necessary to keep the system operating for a long time without being washed-out. Obviously, the most important constraint on the optimization problem is the deviation from the effluent discharge criteria. In the previous study (Balku, 2007) the system variables were predefined according to the basic principles of the waste water treatment system design (Tchobanoglous and Burton, 1991). The local minimum optimal point for the defined optimization problem is determined as 3.7078 and the inequality constraints are all satisfied. The optimization algorithm stops because the change in the objective function is less than the predicted value of the function tolerance and all the constraints are satisfied and they are within the assigned values for the constraint tolerances. ASM3 parameters in the aeration tank are presented in Table 2. The third column shows 
the ASM3 parameters when predefined design parameters are used. The fourth column shows the ASM3 parameters when optimal design parameters are used.

Table 2. ASM3 Parameters in the Aeration Tank

\begin{tabular}{|c|c|c|c|}
\hline \multirow{2}{*}{ Components } & \multirow{2}{*}{ Initial } & \multicolumn{2}{|c|}{ After simulation } \\
\cline { 3 - 4 } & & Pre-defined $(*)$ & Optimum \\
\hline$S_{O}\left(\mathrm{~g} / \mathrm{m}^{3}\right)$ & 0.00 & 3.5 & 2.46 \\
\hline$S_{I}\left(\mathrm{~g} / \mathrm{m}^{3}\right)$ & 30.00 & 30.0 & 30.00 \\
\hline$S_{S}\left(\mathrm{~g} / \mathrm{m}^{3}\right)$ & 100.00 & 0.2 & 0.18 \\
\hline$S_{N H}\left(\mathrm{~g} / \mathrm{m}^{3}\right)$ & 16.00 & 0.4 & 0.40 \\
\hline$S_{N_{2}}\left(\mathrm{~g} / \mathrm{m}^{3}\right)$ & 0.00 & 1.1 & 1.68 \\
\hline$S_{N O}\left(\mathrm{~g} / \mathrm{m}^{3}\right)$ & 0.00 & 19.3 & 18.48 \\
\hline$S_{H C O}\left(\mathrm{gmole} / \mathrm{m}^{3}\right)$ & 5.00 & 2.5 & 2.59 \\
\hline$X_{I}\left(\mathrm{~g} / \mathrm{m}^{3}\right)$ & 25.00 & 1473.6 & 2150.26 \\
\hline$X_{S}\left(\mathrm{~g} / \mathrm{m}^{3}\right)$ & 75.00 & 57.5 & 78.60 \\
\hline$X_{H}\left(\mathrm{~g} / \mathrm{m}^{3}\right)$ & 30.00 & 971.5 & 1347.34 \\
\hline$X_{S T O}\left(\mathrm{~g} / \mathrm{m}^{3}\right)$ & 0.00 & 112.5 & 154.47 \\
\hline$X_{A}\left(\mathrm{~g} / \mathrm{m}^{3}\right)$ & 0.10 & 55.4 & 4194.97 \\
\hline$X_{S S}\left(\mathrm{~g} / \mathrm{m}^{3}\right)$ & 125.00 & 2933.2 & \\
\hline
\end{tabular}

(*) Pre-defined in the previous study (Balku, 2007)

The changes in ASM3 components in the aeration tank with respect to time during the simulations are shown in Figure 2 when the system is operated with the optimized system parameters at a $1000 \mathrm{~m}^{3} /$ day flow rate. The changes in the concentrations of inert particulates, heterotrophic bacteria and suspended solids in the aeration tank can be traced based on the elapsed time. As usual, the concentrations of these three components increase during the start-up period, and then the concentrations of heterotrophs and suspended solids in the aeration tank start to decline due to waste disposal during the conditioning period. In the last period (normal operation), they are tried to be kept constant within the given constraints. The other operational parameters for the activated sludge systems are shown in Table 3 where the treated water characteristics can also be compared. 
Figure 2. Changes in ASM3 Components with Time for Optimized System

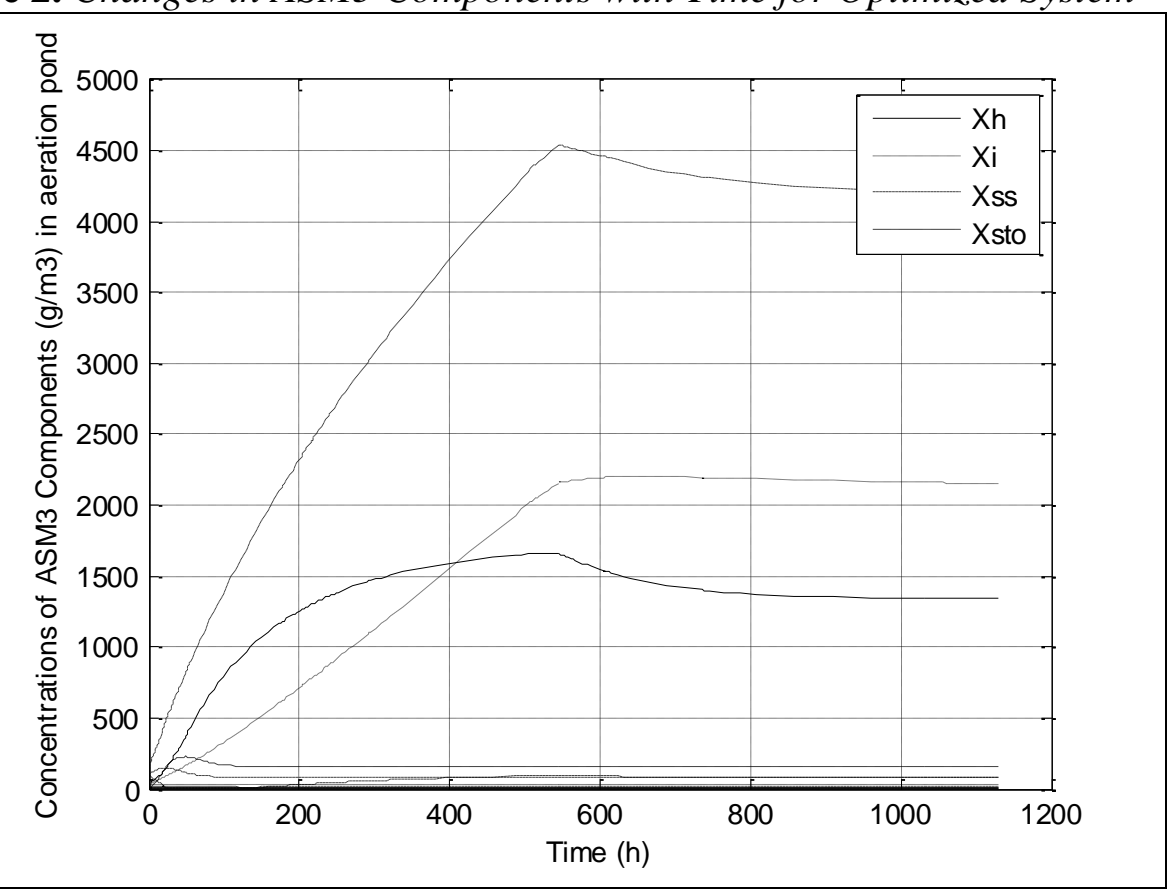

Table 3. Other Design and Operational Parameters

\begin{tabular}{|c|c|c|}
\hline Other Parameters & Predefined $\left({ }^{*}\right)$ & Optimum \\
\hline Inlet Wastewater $\left(\mathbf{m}^{\mathbf{3}} / \mathbf{d a y}\right)$ & $\mathbf{1 0 0 0}$ & $\mathbf{1 0 0 0}$ \\
\hline $\mathrm{k}_{\mathrm{L}} \mathrm{a} 1\left(\mathrm{~h}^{-1}\right)$ & 4.5 & 6.7177 \\
\hline $\mathrm{k}_{\mathrm{L}} \mathrm{a} 2\left(\mathrm{~h}^{-1}\right)$ & 4.5 & 7.2004 \\
\hline Start-up period $(\mathrm{h})$ & 480 & 544.7625 \\
\hline Conditioning period $(\mathrm{h})$ & 480 & 485.9013 \\
\hline Normal Operation Period $(\mathrm{h})$ & 100 & 100.0000 \\
\hline So $\left(\mathrm{g} / \mathrm{m}^{3}\right)$ start-up & 2.99 & 4.8202 \\
\hline So $\left(\mathrm{g} / \mathrm{m}^{3}\right)$ conditioning & 2 & 4.0010 \\
\hline So $\left(\mathrm{g} / \mathrm{m}^{3}\right)$ normal operation period & 2.1 & 2.6441 \\
\hline $\mathrm{MLVSS}\left(\mathrm{g} / \mathrm{m}^{3}\right)$ & 2140.1 & 3046.4 \\
\hline $\mathrm{COD}_{\text {eff }}\left(\mathrm{g} / \mathrm{m}^{3}\right)$ & 37.3375 & 43.1575 \\
\hline $\mathrm{TN}_{\text {eff }}\left(\mathrm{g} / \mathrm{m}^{3}\right)$ & 20.2217 & 19.6897 \\
\hline $\mathrm{SS}_{\text {eff }}\left(\mathrm{g} / \mathrm{m}^{3}\right)$ & 7.8653 & 14.3022 \\
\hline
\end{tabular}

(*) Pre-defined in the previous study (Balku, 2007)

\section{Discussion}

The results achieved by this study are satisfactory and reasonable. The algorithm is run for $1000 \mathrm{~m}^{3} /$ day incoming wastewater volumetric flow rate and for the ASM3 parameters given in Table 2 second column, which are the compositions of the incoming wastewater and the initial compositions of the tanks 
also. The optimization algorithm is performed under the following conditions: the maximum iteration number is set to 50; the maximum function evaluation is 750 ; and the maximum constraints are 0.01 for the objective function, the design variables, and the optimization problem constraints. The optimization algorithm is the 'active-set' option in 'fmincon'.

Continuously changing conditions such as growing or reducing bacteria concentrations and the dissolved oxygen concentration, which varies accordingly with respect to time for an activated sludge system, make the estimation of the design variables difficult in the optimization studies. When an activated sludge model with the complex kinetics and dynamics is combined with a settler model in optimization, the main problem is to determine the initial conditions for the optimization algorithm. In this study, initial conditions for a normal operating period of an activated sludge system are determined in accordance with the optimized design variables. In other words, the initial conditions and the design variables are determined in the same algorithm. Firstly, the incoming waste water is filled in the ponds. Afterwards, the bacteria growth required for the proper settling is maintained in the start-up period. The steady-flow operation is ensured after the conditioning period. During these operations, the initial guesses of the system variables are used. All the processes run under an optimization algorithm and once the simulation algorithm is completed, all the variables are determined and checked whether the constraints are satisfied, if not, new guesses are assigned by the optimization algorithm and resume the simulation. When the optimization algorithm is completed the most important design variables of an activated sludge system such as the aeration pond volume, the aerator power information, the settler tank area, and the recycle and the waste ratios are determined. After the analysis of the results, one can see that prior to the construction of the treatment system the design and the operational conditions can be known for the most economical system. Thus, a simulation method, which includes an optimization algorithm, can be utilized as a good choice and a design tool for an activated sludge system.

One can compare the predefined and the optimum design parameters from Table 4. The comparison of the results show that the volume of the aeration tank, the settler area, the recycle ratio and the waste ratio can be lowered by $26.79 \%$, $49.21 \%, 20.90 \%, 44.42 \%$, respectively and the oxygen transfer rate is increased by $12.11 \%$ by the application of the proposed algorithm. 
Table 4. Design Parameters (Predefined and Optimum)

\begin{tabular}{|c|c|c|}
\hline Design variables/ & Predefined $(*)$ & Optimum \\
\hline Inlet wastewater $\left(\mathbf{m}^{3} /\right.$ day $)$ & $\mathbf{1 0 0 0}$ & $\mathbf{1 0 0 0}$ \\
\hline Aeration tank $\left(\mathrm{m}^{3}\right)$ & 450 & 329.4476 \\
\hline Settler area $\left(\mathrm{m}^{2}\right)$ & 113 & 57.3928 \\
\hline Recycle ratio $\left(\mathrm{Q}_{\mathrm{rs}} / \mathrm{Q}_{\text {in }}\right)$ & 0.8 & 0.6328 \\
\hline Waste ratio $\left(\mathrm{Q}_{\mathrm{w}} / \mathrm{Q}_{\text {in }}\right)$ & 0.012 & 0.0067 \\
\hline $\mathrm{k}_{\mathrm{L}} \mathrm{a} 3\left(\mathrm{~h}^{-1}\right)$ & 4.5 & 5.0448 \\
\hline
\end{tabular}

(*) Pre-defined in the previous study (Balku, 2007)

\section{Conclusions}

In the present study, the predefined system variables which were used in the previous studies are determined by an optimization algorithm. The comparisons of the results are shown in Table 4. From the viewpoint of operating an activated sludge system, both results are acceptable. In terms of economic perspective, the predefined system has an objective function of 5 , whereas the optimized system has a value of 3.7078. As a result, it can be stated that these optimal system design variables provide a better solution in order to have a more economical wastewater treatment system. As optimization solver "fmincon" has been used in solving the defined problem with a three stage simulation algorithm improved. Fmincon solver has four algorithm options; interior-point, trust-region-reflective, SQP (sequential quadratic programming) and active-set. In this study among these options the active-set option has been applied because of its high speed on small to medium sized problems. The objective function is linear, so SQP alternative is not suitable. The trust-region-reflective algorithm also confirms the same results with the active-set algorithm.

The recycle ratio, the waste sludge ratio and the oxygen transfer rate in the aeration pond are the most important parameters in the energy cost and so, the operational cost, and on the other hand the most important parameters of fixed capital investment such as the sizes of aeration and settling tanks and the recycle and waste pumps are minimized in the study. The analysis of the results shows that the investment and operational costs of an activated sludge system can be lowered by using the optimum design parameters which can be determined by an optimization algorithm. The solution gives us local minimum results. The oxygen transfer rate which is obtained higher than the predefined one is related with the capacity and the operational cost of the aerator and it is a very important factor in energy cost. For this reason, when the problem is solved with various initial guesses and other optimization algorithms, one may obtain better results. 


\section{References}

Balku S, Berber R. 2006. Dynamics of an activated sludge process including nitrification and denitrification; Start-up simulation and optimization using evolutionary algorithm. Computers \& Chemical Engineering. 30(3):490-499.

Balku S. 2007. Comparison between alternating aerobic-anoxic and conventional activated sludge systems. Water Research. 41(10):2220-2228.

Balku S. 2014. A Simulation Method for Activated Sludge Systems, International Journal of Scientific and Engineering Research ( IJSER), Volume 5, Issue10, October 2014 Edition (ISSN 2229-5518), 1215-1222.

Balku S, Yuceer MA, Berber R, 2009. Control vector parametrization approach in optimization of alternating aerobic-anoxic systems. Optimal Control Applications and Methods. 30(6):573-584.

Biegler LT, Grossman IE. Retrospective on optimization. Computers \& Chemical Engineering 2004;28(8):1169-1192.

Chachuat B, Roche N, Latifi MA. 2005. Optimal aeration control of industrial alternating activated sludge plants. Biochemical Eng. J. 23:277-289.

Copp JB. The COST Simulation Benchmark: Description and Simulator Manual. http://apps.ensic.inpl-nancy.fr/benchmarkWWTP/Pdf/Simulator_manual.pdf [Accessed 6 August 2013].

Egea J A, Marti R, Banga JR. 2010. An evolutionary method for complex-process optimization. Computers \& Operations Research. 37:315-324.

EU- Council Directive 91/271/EEC. http://bit.ly/1KkPT34 [Accessed 29 August 2006].

EU-Commision Directive 98/15/EEC amending directive 91/271/EEC. http://eurlex.eu ropa.eu/LexUriServ/LexUriServ.do?uri=CELEX:31998L0015:E:HTML [Accessed 29 August 2006].

Ekama GA, Barnard JL, Günthert FW, Krebs P, McCorquodale JA, Parker DS et al. 1997. Secondary settling tanks: Theory, modeling, design and operation. Scientific and Technical Reports No.6. London: IWA.

Ferrer J., Seco A., Serralta, J., Ribes, J., Manga J., Asensi, E., Morenilla, J.J., Llavador, F. 2008. DESASS: A software tool to design, simulate and optimize wastewater treatment plants. Environmental Modelling and Software. 23: 19-26.

Gernaey KV, van Loosdrecht MCM, Henze M, Morten LM, Jørgensen SB. Activated sludge wastewater treatment plant modelling and simulation: state of the art, Environmental Modelling \& Software 2004;19:763-783.

Gujer W, Henze M, Mino T, Loosdrecht M. 1999. Activated sludge model no.3. Water Science and Technology. 39(1):183-193.

Henze M, Gujer W, Mino T, Loosdrecht M. 2002. Activated sludge models ASM1, ASM2, ASM2d, and ASM3. Scientific and Technical Reports No.9. London:IWA Publishing.

Holenda B, Domokos E, Re'dey A', Fazakas J. 2008. Dissolved oxygen control of the activated sludge wastewater treatment process using model predictive control. Computers and Chemical Engineering. 32:1270-1278.

Iqbal J, Chandan GC. Optimization of an operating domestic wastewater treatment plant using elitist non-dominated sorting genetic algorithm. Chemical Engineering Research and Design 2009 87, 1481-1496.

Jeppsson U. Modelling aspects of wastewater treatment processes. 1996. Ph.D.Thesis, Lund Institude of Technology, Sweeden. Available from http://bit.ly/1VB6Jva [Accessed 18 July 2010]. 
Li Z, Qi R, Wang B, Zou Z, Wei G, Yang. 2013. Cost-performance analysis of nutrient removal in a full-scale oxidation ditch process based on kinetic modeling. Journal of Environmental Science. 25(1):26-32.

Rojas J, Zhelev T. 2012. Energy efficiency optimization of wastewater treatment: Study of ATAD. Computers and Chemical Engineering. 38:52-63.

Takács I, Patry GG, Nolasco D. 1991. A dynamic model of the clarification-thickening process. Water Research. 25(10):1263-1271.

Tchobanoglous G, Burton FL. 1991. Wastewater engineering: Treatment, disposal and reuse. 3rd ed. McGraw-Hill. p.1334.

The Mathworks: Optimization Toolbox. www.mathworks.com. [Accessed 24 August 2006].

\section{Nomenclature}

MLVSS mixed liquor volatile suspended solids

COD chemical oxygen demand

TN total nitrogen

SS suspended solids

\section{Activated Sludge Model 3 (ASM3) Components}

$\begin{array}{ll}S_{O} & \text { dissolved oxygen concentration } \\ S_{I} & \text { inert soluble organic material } \\ S_{S} & \text { readily biodegradable organic substrate } \\ S_{N H} & \text { ammonium plus ammonia nitrogen } \\ S_{N_{2}} & \text { dinitrogen } \\ S_{N O} & \text { nitrate plus nitrite nitrogen } \\ S_{H C O} & \text { alkalinity } \\ X_{I} & \text { inert particulate organics } \\ X_{S} & \text { slowly biodegradable substrates } \\ X_{H} & \text { heterotrophic biomass } \\ X_{S T O} & \text { organics stored by heterotrophs } \\ X_{A} & \text { autotrophic, nitrifying biomass } \\ X_{S S} & \text { total suspended solids }\end{array}$

